\title{
Simpson Grade 3
}

National Cancer Institute

\section{Source}

National Cancer Institute. Simpson Grade 3. NCI Thesaurus. Code C128619.

Macroscopically complete removal of the intradural tumor, without resection or coagulation of its dural attachment or its extradural extensions. 